\title{
Alternativas orgánicas como una resistencia a la globalización neoliberal
}

Palabras clave: Campesinado, Unidad Económica Campesina, Pluriactividad.

\author{
Ana Karen Andrade López, Mildred Espinoza Santiago, \\ Dalia López Téllez, Teresa de Jesús Morales Pérez, Omar Pascua Peña ${ }^{1 *}$ \\ y Lourdes Garcia Martínez ${ }^{2}$
}

De acuerdo con Sánchez (2015), los planteamientos de Chayanov (1974) se refieren a la sociedad rusa en un periodo histórico determinado, pero sus aportaciones tienen como finalidad comprender el funcionamiento de la Unidad Económica Campesina, que obra a partir de las necesidades de consumo de sus integrantes. Asimismo, el trabajo realizado está en relación directa con su capacidad de satisfacción de dichas necesidades, lo cual también se conoce como nivel de autoexplotación.

1 Estudiantes de la Licenciatura en Ciencias Sociales y Sociología Rural del Instituto de Investigaciones Sociológicas de la Universidad Autónoma "Benito Juárez" de Oaxaca. *Correo electrónico del autor de correspondencia: omrpp97@gmail.com

2 Estudiante de la Licenciatura en Ciencias Sociales y Desarrollo Regional del Instituto de Investigaciones Sociológicas de la Universidad Autónoma "Benito Juárez" de Oaxaca. 
Chayanov (1974) analiza la lógica de la Unidad Económica Campesina con base en criterios como el tamaño de la parcela, el tipo de cultivo al que se dedican, el tamaño de la familia, sus conductas de consumo y las actividades comerciales o artesanales que realizan, además de la agricultura. Dicha perspectiva permitió identificar y como consecuencia elegir el sujeto/objeto de estudio y sentó las bases para el análisis del mismo. Con la finalidad de lograr esta investigación, se realizó un reconocimiento y análisis de la constitución y composición de la Unidad Económica Campesina; es decir, la familia Paz Avendaño que dirige el señor Hilario.

De acuerdo con Chayanov (1974), aun si se atribuyera mucho valor a alguno de los factores determinantes de la Unidad Económica Campesina y la influencia de éstos, el interés se debe centrar en la mano de obra y reconocerla como el elemento organizativo de cualquier proceso de producción. De la misma manera, se ha de entender que la unidad económica familiar no recurre a la fuerza de trabajo contratada, de modo que la composición y el tamaño de la familia determina la cantidad de la fuerza de trabajo, la división y la asignación de la actividad. Por ello, según Chayanov, se debe aceptar que el carácter de la familia es uno de los factores principales de la Unidad Económica Campesina (1974).

A partir de las reflexiones que se realizaron con base en la perspectiva de Chayanov (1974), para analizar el funcionamiento de la Unidad Económica Campesina decidimos realizar una investigación breve, apenas un acercamiento de cómo funciona una Unidad Económica Campesina en San Pablo Huitzo.

La familia de Hilario Paz se conforma por seis integrantes (incluido él): su esposa María, dos menores de edad (de 15 y 17 años) que estudian en el COBAO Plantel 42 Huitzo y dos hijos mayores, que estudian en la Universidad de Chapingo. Al respecto, cabe resaltar que dicha universidad está encargada de la enseñanza e investigación en las ciencias agronómicas y ambientales, enfocadas principalmente en el desarrollo del medio rural.

Hilario Paz (entrevistado el 8 de enero de 2018) se dedica a la cosecha del campo, a la venta de los productos que él y su familia siembran durante todo el año, a la crianza de animales de traspatio y suele trabajar de albañil cuando no tiene labores en el campo.

La economía de la familia campesina necesita realizar actividades complementarias, lo cual es un fenómeno que ha existido desde el pasado y se ha empezado a conocer como pluriactividad. Diversos teóricos, como Grammont (2009), han explicado esta labor como la combinación de actividades y 
empleos de diversa índole generados en condiciones y espacios distintos de los del campo y revelan una gran participación de la mujer, cuyo trabajo ha pasado de ser considerado una actividad complementaria con una marcada jerarquía de género y generación, a estrategias de supervivencia y resistencia en las que se desdibujan tales jerarquías.

Dicha pluriactividad permite a Hilario Paz mantener a su familia; por ello, sus niveles de autoexplotación han sido siempre en función de sus necesidades y las de su familia. En ese orden de ideas, la medida de autoexplotación depende en mayor grado del peso que ejercen en el trabajador las necesidades del consumo de su familia (Chayanov, 1974). El consumo no solo se debe entender en el sentido estricto de la palabra, sino también la autoexplotación que ocurre en la medida en que esas necesidades son materiales y económicas, porque sus hijos estudian y requieren cierto apoyo económico para continuar en la escuela.

Cabe recordar que el modelo campesino de producción-consumo se sustentaba en siete pilares: posesión o usufructo de la tierra, producción agrícola de autoconsumo, intensificación del factor trabajo, reducida necesidad de dinero, abundancia y permanencia de hijos que muy pronto se convertían en trabajadores, aportación de trabajo por todos los miembros del grupo doméstico, y aceptación indiscutible de las jerarquías de género y generación (Chayanov, 1974, citado en Arias, 2013, p. 102).

Por lo anterior, Hilario Paz (en enero 8 de 2018) y su esposa realizaban las siguientes actividades: preparar el terreno para la siembra, arar, sembrar, regar y vender la cosecha. En conjunto, sus hijos también llevan a cabo algunas labores, las cuales se dividen o asignan en función de la edad, el tiempo y el conocimiento de los hijos, es decir, los menores se dedican a arrancar la hierba silvestre, desgranar maíz y cuidar a los animales de traspatio. En cuanto a los hijos mayores, ayudan sólo en el periodo vacacional, como se mencionó anteriormente, se encuentran estudiando una carrera universitaria, lo cual provoca una migración temporal al Estado de México.

En términos de Chayanov (1974), la fuerza de trabajo de la unidad de explotación doméstica está determinada por la disponibilidad de miembros capacitados en la familia, así como por el volumen de la actividad y la cantidad de trabajo proporcional al número de miembros activos de la familia. De acuerdo con esto, el tamaño y la composición familiar ejercerán su influencia en la organización de la unidad económica no sólo cuantitativamente, sino también cualitativamente. 
Ahora bien, para hablar del campo mexicano, es necesario mencionar que en las últimas décadas éste ha vivido una serie de problemas derivados de la globalización neoliberal, lo cual ha generado la transformación del campo. Algunos han surgido a raíz de la apertura mercantil que trae consigo el Tratado de Libre Comercio de América del Norte (TLCAN) en 1992; sin embargo, dicho tratado ha cumplido con el propósito de incrementar la productividad agricola pues beneficia a quienes más tienen y deja afuera a los que realmente lo necesitan, lo cual propicia un problema para los pequeños productores.

Asimismo, vale la pena hablar no sólo de la transformación que ha sufrido el campo, sino también de la transición de una sociedad agraria organizada en torno a la actividad primaria hacia una sociedad rural más diversificada.

La falta de apoyos o el difícil acceso a éstos debido a los requisitos que muchas veces se convierten en un problema para los productores porque no cuentan con ellos, además de los altos costos de insumos y servicios, las pérdidas por cuestiones climáticas y plagas, la falta de capacitación, la pérdida de fertilidad del suelo y la escasez y contaminación de agua son algunos problemas que afectan actualmente al campo mexicano.

Ante esas transformaciones que enfrentan los campesinos, han surgido preocupaciones por impulsar un desarrollo sustentable, basado en la medida de lo posible en no depender de insumos que puedan afectar la tierra y al mismo tiempo tener la capacidad de comprarlos. Por ello, la familia del señor Hilario ha recurrido a estas nuevas prácticas al rechazar el uso de plaguicidas y agroquímicos, los cuales representan un problema para productores y consumidores.

Debido a la conciencia acerca de lo sustentable y orgánico que poco a poco se ha vuelto parte de la forma de producir de los campesinos, se ha reflexionado profundamente en los daños que ocasionan los elementos químicos. En el caso del señor Hilario (en enero 8 de 2018), él produce su propio fertilizante a base de microorganismos de la montaña mediante una mezcla de hojas y tierra fresca, los cuales se combinan con salvado y melaza. Finalmente, se le pone una vela y se deja reposar durante dos meses.

El objetivo del señor Hilario (en enero 8 de 2018) era producir alimentos sanos y acceder a un espacio digno donde pueda vender sus productos. Al querer introducir sus productos al mercado y competir con otros vendedores o revendedores, se ha enfrentado a la lógica de la oferta y la demanda; no obstante, ello hace que se manifieste una saturación de productos y se genere una depreciación de los precios, pues muchos productos que se ofertan 
en la Central de Abastos provienen de grandes empresas extranjeras, las cuales ejercen un control sobre el mercado y los precios.

Rubio (2004), en su texto El sector agropecuario mexicano frente al nuevo milenio, menciona dos formas principales de dominio que establecen las grandes empresas agroindustriales trasnacionales sobre los productores rurales: a) el dominio mediante los mecanismos de precios, y b) el control de la comercialización y distribución de los cultivos predominantes.

Pese al dominio que ejercen las grandes empresas en el precio y la calidad de los productos, se puede ver una enorme diferencia, porque los productos locales que ofrece el señor Hilario son totalmente orgánicos, pues no utiliza químicos para el proceso de crecimiento o maduración, ni para eliminar o controlar las plagas. Con esto crea una nueva forma de relacionarse con la tierra.

Cuando se habla del control de comercialización y distribución de los productos de vanguardia, el señor Hilario muestra cómo este mercado incorpora al productor a una lógica dominante de oferta y demanda, la cual genera un abandono de ciertos cultivos que suelen no tener demanda o que han sido invisibilizados a causa del control ejercido sobre el mercado por las grandes empresas. Sin embargo, la familia del señor Hilario no abandona del todo los cultivos con menos demanda, con lo cual genera resistencia.

Durante la entrevista, el señor Hilario (realizada el 8 de enero de 2018) mencionó que durante un año recibió apoyo del gobierno por medio del programa (PROCAMPO). ${ }^{3}$ Dichos recursos llegaban a destiempo, lo cual generó otros problemas; por ejemplo, en caso de contar con otro tipo de apoyo federal, éste es utilizado para el campo, lo que reduce el destinado a sus necesidades; además, se les obliga a sembrar un solo cultivo y a utilizar productos químicos, lo cual provoca la erosión del suelo.

Durante el año que recibió el apoyo, en la comunidad hubo casos de intoxicación, debido al mal manejo de los productos químicos en el tomate, ya que a los productores no se les enseñó cómo utilizar debidamente estos insumos químicos.

Ante tales problemas, el campo mexicano ha comenzado a reformular alternativas, como retomar prácticas tradicionales alejadas del uso de los productos químicos, para lo cual ha puesto en práctica técnicas agrícolas

3 El Programa de Apoyos Directos al Campo (PROCAMPO) tiene como objetivo complementar el ingreso económico de los productores del campo mexicano, para contribuir a su crecimiento económico individual y al del pais 
amigables con el ambiente y conocimientos empíricos, así como capacitación especializada para tener mayor conocimiento de sus tierras y la manera de aprovecharlas sin dañar el ambiente y su salud, todo ello como parte del proceso de resistencia. La situación y los problemas aquí descritos generan consecuencias en el funcionamiento de la unidad campesina; sin embargo, el caso de la familia del señor Hilario es una manifestación tanto de las resistencias que se tienen como de una lucha que no se debe abandonar.

\section{Referencias}

Arias, P. (2013), Migración, economía campesina y ciclo de desarrollo doméstico. Discusiones y estudios recientes, Estudios demográficos y urbanos, 28 (1), 93-121. Recuperado de http://www.redalyc.org/pdf/312/31230009003.pdf

Chayanov, A. (1974), La organización de la unidad económica campesina, Buenos Aires: Nueva Visión SAIC.

Grammont, H. (2009), La desagrarización del campo mexicano, Convergencia, 16 (50), 13-55. Recuperado de https://www.redalyc.org/pdf/105/10511169002.pdf

Paz, H. (2018), Recopilación de entrevista oral en la comunidad de San Pablo Huitzo, Oaxaca", 9 de enero.

Rubio, B. (2004), El sector agropecuario mexicano en los años noventa: subordinación desestructurante y nueva fase productiva, en El sector agropecuario mexicano frente al nuevo milenio, México: IISUNAM/Plaza y Valdés Editores.

Sánchez, J.G.K. (2015), Los pequeños cafeticultores de Chiapas. Organización y resistencia frente al mercado, México: Cesmeca-Unicach. 